\title{
Analysis of the Current Situation of Tibetan College Students' English Acquisition in the Trilingual Environment and the Countermeasures
}

\author{
Lan-fen Ji \\ School of Foreign Language \\ Qinghai Normal University \\ Xining, China \\ jilanfen@qhnu.edu.cn
}

\author{
Dian-jun Lu \\ School of Mathematics and Statistics \\ Qinghai Normal University \\ Xining, China \\ ldj@qhnu.edu.cn
}

\begin{abstract}
In the process of English acquisition, minority students are inevitably influenced by their first language and Chinese, which causes the complexity of learning. This paper analyzes the current situation of Tibetan college students' English acquisition in the trilingual environment and then proposes some effective coping strategies.
\end{abstract}

Keywords-Trilingual environment; Tibetan students; English acquisition; strategies

\section{INTRODUCTION}

With the continuous promotion and development of English education, the problem of trilingual education in ethnic minority areas has become increasingly prominent. The relationship between trilingual education and the harmonious development of minority languages has been well-coordinated, Chinese and English in ethnic areas has been related to national unity and economic development in ethnic areas. It is also related to the individual development of every student from a minority area. Therefore, the issue of trilingual harmonious education in ethnic areas has become an issue that needs to be studied and solved. Relevant research should be mentioned on the agenda.

\section{A GENERAL SITUATION OF TRILINGUAL EDUCATION IN WESTERN ETHNIC AREAS}

Education and teaching planning in Tibetan autonomous prefectures are basically the same, that is, Tibetan language and Chinese are opened from the first grade of primary school, and English is opened from the third grade of primary school. The textbook in Tibetan is a national Tibetan-specific textbook published by Qinghai Nationalities Publishing House. The teaching language is Tibetan. Chinese textbooks are special textbooks for Tibetans in the People's Education Edition. The teaching language is Chinese; the English textbooks use the general textbooks of people's education, and the teaching language is Tibetan or Chinese. Tibetan, Chinese and English are all opened till high school.

In the universities in western areas, except for students majored in minority languages, other minority students do not

The research was partly supported by the key project of national education scientific planning ministry of education Research on Trilingual Teaching Model and Multicultural Classroom Construction in Qinghai Tibetan Areas (DMA150219); by National Social Science Foundation Project (19BYY223). need compulsory or elective minority language courses, but college Chinese and college English are compulsory courses. College Chinese is opened in freshman and the sophomore year. Although the CET-4 is not directly linked to the degree, the importance is attached to English by Chinese education in the past 20 years. Whether a student has passed the or not the CET 4 has become an important basis for judging whether a university student is qualified or not.

\section{RELATED THEORY}

\section{A. Trilingual acquisition}

Language transfer can occur in a third language acquisition process or among multiple languages. As a new field emerging from the development of migration theory, the study of the third language acquisition began in 1987, and Ringbom studied monolingual in the Finnish language in the monograph "The Role of First Language in Foreign Language Learning". A comparative analysis of English learning between bilingual learners and bilingual learners found that bilingual learners are better than monolingual learners [1].

Kingbom also pointed out that in the process of trilingual acquisition, due to the simultaneous emergence of multiple languages, the familiarity of various languages must be taken into account. Odlin also suggested that the two languages that learners have mastered will have an effect on third language acquisition. The pronunciation, vocabulary, and grammar of the first language and the second language all influence the acquisition of the third language. The pronunciation of the first language has the greatest impact on the learning of thirdlanguage pronunciation. In terms of vocabulary, Cenoz believes that the closer the mother tongue and the target language approach in type, the more likely they are to borrow the third language vocabulary, the most common of which is the actual word;

Compared with L1 and L2 acquisition, the L3 language ability is more complicated, It is mainly reflected in the impact on cross-language, such as interference, avoidance, reverse transfer, inter-languages, code-switching and other phenomena [2]. Cenoz also pointed out that many factors can cause the transfer of mother tongue, such as language distance, language 
type, language learning order, language familiarity, learner's age, etc[2]. Compared with the Han nationality area, students from ethnic minority areas are affected by both Chinese and national languages in the process of third language acquisition. Therefore, they face more difficulties and problems in English learning. This requires us to adopt different teaching strategies to promote trilingual acquisition.

\section{B. Mother tongue transfer}

In the process of second language learning, mother tongue transfer is an inevitable phenomenon. Effective role of mother tongue transfer can promote second language acquisition. Native language transfer has been an important research topic in the field of second language acquisition and applied linguistics since it was proposed in the 1950s. L1 Transfer refers to the influence exerted by learners' language learning habits and native language knowledge on second language learning in the process of language learning. Weinreich proposed that in the process of language learning, when L1 and L2 are similar, the positive transfer will be generated and the acquisition of a second language will be promoted [3].

On the contrary, when there is a difference between the native language (L1) and the target language (L2), it will cause negative transfer, which will interfere with or hinder the understanding and mastery of the second language. Since the 1950s, the field of second language acquisition has experienced two historical stages: contrastive analysis hypothesis and interlanguage hypothesis. The hypothesis of contrastive analysis overstates the negative effects of mother tongue on the second language and holds that the main obstacle to second language acquisition comes from the interference of the mother tongue. Terence Odlin points out that phonetics, syntax, writing system and other aspects will affect the current language learning and produce transfer errors, among which the transfer of word order in syntax is particularly prominent [4]. Behaviorist $\mathrm{Hu} \mathrm{Li}$ believes that errors in language are the negative transfer caused by some habits in learners' mother tongue [5]. After the 1980s, the study of mother tongue transfer experienced new development. Based on cognitive science, Kellerman discusses the role of mother tongue transfer in second language acquisition from the perspectives of language, society and psychology [6]. Liao Genfu found in his experiments with students in JiangXi University of Science and Technology that in the process of second language acquisition, the negative transfer of mother tongue and the difference between mother tongue culture and English will make it difficult for learners to distinguish container verbs with graphics as object and content verbs with background as object, thus affecting learners' acquisition on orientation construction [7].

\section{Analysis of The Status QuO OF TiBetan College STUDENTS' ENGLISH ACQUISITION IN THE TRILINGUAL ENVIRONMENT}

\section{A. Lack of good language environment}

American linguist Krashen pointed out that the acquisition of new language structures requires continuous input. Only when the input reaches a sufficient amount can the conversion of language ability change from quantitative to qualitative change [8]. In other words, if students really learn A new language structure requires a long period of reading and a large number of listening exercises for the content of interest, so that language acquisition can be realized. Ellis believes that "input", "absorption" and "output" are the three most important factors in the process of second language acquisition. L2 learners' participation in social and external interaction activities is the main source of internal cognitive mechanism development [9]. Tibetan college students speak their mother tongue from an early age and basically communicate in their mother tongue in daily communication.

Therefore, it is impossible for Tibetan college students to learn Chinese and English completely from their mother tongue. Through interviews, Tibetan students began to learn Chinese from elementary school. Teachers spent most of their time in national languages. They only used Chinese when they read texts and explained texts, and then returned to national languages after class. Moreover, compared with children in developed areas, Tibetan students began to contact English in the third grade of elementary school, and the time for English learning was too short. English is different from Chinese and different from the mother tongue. For students in minority areas, in the process of learning English, the characteristics of the mother tongue will inevitably be brought to English. This way of thinking in the mother tongue is very difficult for learning English.

According to The Contrasive Analysis Hypothesis, when the learner's native language rules are inconsistent with the target language, the native language features will appear in the target language, leading to the negative transfer of the target language learning. The Sapir-Whorf Hypothesis argues that language structure determines the way people think. The way people observe and perceive the objective world depends on the lexical structure of the language. The difference between the national language and the English syntactic structure is likely to cause confusion in the expression and understanding of minority students. This difference also affects the formation of English thinking mode to a certain extent.

\section{B. Increased difficulty from trilingual conversion}

From the perspective of the language system, English belongs to the Indo-European language family. Tibetan is an independent branch language of the Tibetan-Burmese language branch of the Sino-Tibetan language family. The differences between different languages are still relatively large. According to the interview, $75 \%$ of Tibetan college students feel that the English word order is complicated and it is difficult to learn. This is because the word order of Tibetan and Chinese English is different.

The word order of Tibetan is roughly divided into two types: (1) S-O-V (subject-object-predicate) structure; and (2) $\mathrm{S}-\mathrm{V}$ (subject-predicate) structure. The first structure is more widely used (see Table 7); the second is mainly used for shorter daily communication or conversations. Furthermore, although the normal word order structure of both English and Chinese sentences is SVO (subject-predicate-object) structure, for time and place adverbials. According to codes of English, 
we first consider the place and then the time, which is the opposite of Chinese. Therefore, minority students often feel at a loss in Chinese-English conversion.

The difference in syntactic structure will, to a large extent, interfere with the learning language of Tibetan students, causing confusion in their understanding and expression, especially in English composition and sentence translation. In general, English-language books sold in China are mostly interpreted in Chinese and English. Most of the network training courses are mainly taught in Chinese and English. In the process of learning English, Han students only need to overcome the obstacles from Chinese, but for minority students, the mother tongue is the first language, Chinese is the second language, and English is their third language. They need to avoid interference from the mother tongue and they also need to avoid the influence of Chinese. In the conversion of the three languages, problems like information ambiguity, information missing will appear, resulting in the complexity of learning. In the questionnaire survey, Tibetan students with good Chinese language skills are obviously better than those with the poor Chinese language. Therefore, ethnic students should learn Chinese well first, understand the differences between Chinese and English, and form a good English language habit.

\section{COUNTERMEASURES}

In view of the current situation of English learning of students in minority areas, the study proposes that teachers and schools work together to help students in ethnic areas establish correct learning motivation.

\section{A. School aspects}

\section{1) To create a favorable language teaching environment}

Attachment to the mother tongue is a major obstacle for ethnic students to learn English, so it is necessary to create an English language environment for students. On one hand, schools should be equipped with multimedia teaching equipment to encourage English teachers to use audio-visual equipment in the classroom, to play some English texts, audio and video for students during the class, so that students are immersed in the English language environment, which not only stimulates students to learn English. The interest can make them learn English more and more naturally. On the other hand, schools should also actively carry out the second English class, such as English Corner, English Speech Contest, English Evening, extending English outside the classroom, allowing students to use English as much as possible, creating opportunities to input and output English for students. Swain pointed out that second language acquisition is a two-way communication activity. Simple language input is not enough. Only the combination of input and output can promote second language acquisition [10].

\section{2) To improve the professional quality of teachers}

Due to the special environment in the ethnic areas, English teachers must have the general qualities of teachers and the special qualities of English teachers in minority areas. According to teacher interviews, there are widespread problems in English-speaking areas such as low academic qualifications, poor teaching experience and irrelevant majors. The professional quality level of teachers will directly affect the quality of English teaching in ethnic areas. If the professional quality of English teachers does not meet the requirements, students will gradually lose confidence and interest in learning English. The non-standard pronunciation will be a life-long situation. Therefore, schools should speed up the construction of qualified teaching staff and promote their training and professional skills.

\section{B. Teacher aspects}

\section{1) To change the concept of teaching}

Through professional development, language teachers can not only achieve the teacher's personal goals, but also achieve the goals of the college, and the two can complement each other [11]. Teachers should strive to improve their professional level, establish the concept of lifelong learning, and use effective knowledge growth as a guarantee for teaching and research. On the basis of formulating professional development plans, teachers themselves must be proactive and actively construct knowledge structures. For example, ensure that teachers can read 2 books, write 2 research papers, or improve their teaching every semester. Secondly, in the process of multiple language teaching, teachers should pay attention to respect the differences of language, follow the rules of language, and gradually help students to establish a learning system. At the same time, in the design of teaching content, language processing theory can be adopted, from easy to difficult, from simple to complex, encourage learning and learning more, and adapt to the learning environment of multiple languages as soon as possible. In addition, in the design of teaching, teachers should pay close attention to the language errors often made by students, and constantly analyze and summarize the negative transfer errors of these languages, so as to design targeted exercises for students. Lado pointed out that teachers who have conducted a comparative analysis of both mother tongue and foreign language will be more aware of the problems in student learning and adopt a more effective method to solve them [12]. Finally, teachers should make use of the commonality of mother tongue culture and foreign language learning to enable students to cross differences and improve intercultural communication skills, thus minimizing the impact of mother tongue culture on negative language transfer.

\section{2) To enhance the internal drive of students' learning} motivation

Ellis, R. The motivation for learning comes from the learner's expectation of the possibility of success or interest in what he has learned and the sense of accomplishment that he has achieved through his efforts, and confirms the interaction and mutual interaction between motivation and language learning outcomes[13]. Psychologist Piaget believes that a job based on certain interests can achieve results.

Gao Yihong's research found that the motivation of Chinese college students' English learning mainly consists of achievements, going abroad, social responsibility, personal development, internal interests and information media, which laid the foundation for the basic theory of learning motivation in domestic implementation and development [14]. Therefore, 
it is imperative that teachers should help students in minority areas to establish a correct view of learning and enhance their driving force for learning motivation. They can start from two aspects: close-range motivation and long-term motivation to help students overcome internal and external interference and learn English well. For close-range motivation, teachers can emphasize to students that learning English well is not only beneficial to have scholarships, but also for being appraised merit students. For long-term motivation, teachers can publicize to students that the implementation of the country's strategy for the development of the western region, the western region is facing tremendous opportunities. In the future, the western region will become a hot spot for foreign tourists and foreign investors. Doing business in a country where English is a business language has an advantage in a highly competitive society.

\section{Student aspects}

\section{1) To change learning concepts and optimize learning} strategies

Tibetan students must change their learning concepts on English learning, teachers stimulate their motivation, and strive to improve their initiative. Students should develop their learning plans and learning goals in line with their English proficiency and goals, learn English according to defined learning goals and plans, and achieve the desired goals. Students will achieve success and increase their confidence in learning and be clear about the direction of future efforts. In addition, students should choose their own learning strategies according to their study habits and learning styles, and often reflect on the progress of learning and the effectiveness of strategies, and make timely adjustments. Through the rational use of learning strategies, master the learning rules, cultivate good English learning habits, pay attention to the improvement of learning methods, and thus improve learning efficiency.

2) To treat differences in multilingual and multicultural contexts correctly

Language is the carrier of culture, culture is the base of language, and the relationship between language and culture is inseparable. Language and culture blend together and complement each other. Only learning the language without understanding the culture on which it depends is equal to the rootless wood and passive water. Lian Shuneng pointed out in the "English-Chinese Comparative Study: "Familiar with the characteristics of foreign languages and mother tongues, and scientifically compare them to analyze the factors of their differences, which will undoubtedly help to determine the key points and difficulties of teaching, enhance the predictability and pertinence of teaching, thus improving the effectiveness of teaching". As a national college, both teachers' teaching and students' learning of language cross-cultural awareness should be paid attention to. It can not only avoid cultural conflicts and unnecessary cultural misunderstanding, it can also stimulate students' interest in learning language and culture, thus improving the overall English teaching level of ethnic colleges and universities. For Tibetan students in this study, Tibetan culture has a unique cultural heritage and rich religious features. However, the teachers who undertake foreign language teaching are almost all non-Tibetan teachers, and most teachers do not know enough about Tibetan culture. Therefore, for the English learning of Tibetan college students in our college, cultural differences have greatly affected and restricted the effect of English learning. Correctly treating the cultural differences between Tibetan and Chinese, using contrastive learning methods to strengthen cross-cultural awareness and enhance sensitivity to cultural differences is essential for improving English learning and learning efficiency.

\section{CONCLUSION}

Trilingual teaching is not a simple translation of Tibetan, Chinese and English languages, but an exchange of learning between different cultures. In the process of language learning, through scientific and effective strategies, language transformation and development can be realized at higher levels. In the future trilingual teaching, the implementation of the teaching strategy needed to construct the harmonious ecology of trilingual should be placed in a more prominent position and sequence.

\section{REFERENCES}

[1] Ringbom $\mathrm{H}$. The Role of the First Language in Foreign Language Learning[M]. Clevedon, Philadelphia: Multilingual Matters, 1987.

[2] Cenoz J, Hufeisen B, Jessner U. Cross-linguistic Influence in Third Language Acquisition: Psychological Perspectives[C]. Clevedon: Multilingual Matters Ltd, 2001.

[3] Weinreich U. Languages in contact: findings and problems[M].New York: Linguistic Circle of New York,1953.

[4] OdlinT. Language transfer: Cross-linguistic influence in language learning [M]. ShangHai: Shanghai Foreign Language Education Press, 2001

[5] Li Hu. Negative Transfer of Mother Tongue in Second Language Acquisition[J]. Scientific and Technological Information, 2008,(20):12 15.

[6] Kellerman E. Crosslinguistic Influence: Transfer to nowhere?[J]. Annual Review of Applied Linguistics,1995(15):125-150.

[7] Genfu Liao. An Analysis of the Acquisition of English Orientation Construction by English learners in China[J]. Academic Forum, 2016(11):176-180

[8] Krashen D. Principles and Practice in Second Language Acquisition[M]. New York: Pergamon Press Ltd, 1982

[9] Ellis R. Understanding Second Language Acquisition [M]. Oxford: Oxford University Press, 1985.

[10] Swain M. Communicative Competence: some roles of comprehensible input and comprehensible output in its development [J]. MA: Newbury, House.1985:235-236

[11] Richards, J. \& T. Farrell. Professional Development for Language Teachers: Strategies for Teacher Learning[M]. London: Cambridge University Press, 2005.

[12] Lado R. Linguistics Across Cultures [M].Ann Arbor: University of Michigan Press, 1975

[13] Ellis R. The Study of Second Language Acquisition [M]. Oxford: Oxford University Press, 1994.

[14] Yihong Gao, Ying Cheng, Yuan Zhao. The Relationship between Motivation Types and Motivation Intensity in English Learning: a Quantitative study of College students[J]. Foreign Language Research, 2003,(2):60-64 